\title{
The prognostic value of combined TGF- $\beta 1$ and ELF in hepatocellular carcinoma
}

Fei $\mathrm{Ji}^{1+}$, Shun-Jun Fu ${ }^{2+}$, Shun-Li Shen ${ }^{3}$, Long-Juan Zhang ${ }^{4}$, Qing-Hua Cao ${ }^{5}$, Shao-Qiang Li ${ }^{3}$, Bao-Gang Peng ${ }^{3}$, Li-Jian Liang ${ }^{3}$ and Yun-Peng $\mathrm{Hua}^{3^{*}}$

\begin{abstract}
Background: Tumor suppression of Transforming Growth Factor (TGF- $\beta$ ) signaling pathway requires an adaptor protein, Embryonic Liver Fodrin (ELF). Disruption of ELF expression resulted in miscolocalization of Smad3 and Smad4, then disruption of TGF- $\beta$ signaling. However, the prognostic significance of ELF for hepatocellular carcinoma (HCC) hasn't been clarified. This study aimed to investigate whether measuring both TGF- $\beta 1$ and ELF provides a more powerful predictor for HCC prognosis than either marker alone.

Methods: TGF- $\beta 1$ and ELF protein were detected by immunohistochemistry. The relationship between TGF- $\beta 1 / E L F$ expression and patients' clinicopathologic factors was analyzed. The association between TGF- $\beta 1 / E L F$ expression and disease-free survival and overall survival was analyzed by Kaplan-Meier curves, the log-rank test, and Multivariate Cox regression analyses.

Results: The expression of TGF- $\beta 1$ in HCC tissues was significantly higher than that in normal liver tissues. Conversely, the expression of ELF in HCC tissues declined markedly. ELF protein was correlated with HBsAg, tumor size, tumor number, TNM and recurrence. Data also indicated a significant negative correlation between ELF and TGF- $\beta 1$. Patients with high TGF- $\beta 1$ expression or/and low ELF expression appeared to have a poor postoperative disease-free survival and overall survival compared with those with low TGF- $\beta 1$ expression or/and high ELF expression. Furthermore, the predictive range of ELF combined with TGF- $\beta 1$ was more sensitive than that of either one alone.

Conclusions: TGF- $\beta 1$ and ELF protein are potential and reliable biomarkers for predicting prognosis in HCC patients after hepatic resection. Our current study has demonstrated that the prognostic accuracy of testing can be enhanced by their combination.
\end{abstract}

Keywords: Transforming growth factor, Embryonic liver fodrin, Hepatocellular carcinoma, Prognosis, Biomarkers

\section{Background}

Hepatocellular cancer (HCC) is one of the most common, aggressive malignancies, the third leading cause of cancer-related deaths worldwide (World Health Organization Report, 2006) [1-3]. Although surgical resection, percutaneous ablation and liver transplantation are considered as the curative treatments for HCC, the long-term prognosis of patients undergoing potentially curative treatments is still poor. Fully $60 \%$ to $70 \%$ of patients develop recurrence or metastasis within 5 years after resection $[4,5]$. It is therefore a very important and

\footnotetext{
* Correspondence: hyp0427@163.com

${ }^{\dagger}$ Equal contributors

${ }^{3}$ Department of Liver Surgery, the First Affiliated Hospital, Sun Yat-sen University, Guangzhou 510080, P. R. China

Full list of author information is available at the end of the article
}

urgent task to find an effective biomarker to identify patients with a high risk of recurrence or metastases, and provide personalized therapy according to the predicted risk of recurrence.

The transforming growth factor $\beta$ (TGF- $\beta$ ) signaling pathway is known to play an important role in multiple cellular processes, including cell growth, differentiation, adhesion, migration, apoptosis, extracellular matrix formation and immunosuppressant [6-9]. TGF- $\beta$ signals are conveyed from type I and type II transmembrane serine/ threonine kinase receptors to the intracellular mediatorsSmad2 and Smad3, which further complex with Smad4, translocate to the nucleus and bind to Smad-binding elements (SBE) in target gene promoters, thereby activating its targets, such as p21, p15, p16, p27 [10-14]. TGF- $\beta$ is 
particularly active as a profound tumor suppressor by prohibiting cell cycle progression and arresting cells in early G1 phase. However, misregulation of TGF- $\beta$ signaling promotes tumor growth and invasion, evasion of immune surveillance, and cancer cell dissemination and metastasis [11-14]. In HCC tissues, the overexpression of TGF- $\beta 1$ was found and correlated with carcinogenesis, progression, and prognosis of HCC, while normal hepatocytes had not any TGF- $\beta 1$ staining [15]. In our previous study, we found hepatocarcinogenesis could be closely related to the low expression of Smad4 and phosphorylated Smad2, and the high expression of TGF- $\beta 1$ and Smad7 in advanced stage of liver cirrhosis [16].

Embryonic Liver Fodrin (ELF), also named as $\beta 2$ spectrin $(\beta 2 \mathrm{SP})$, first isolated from foregut endodermal stem cell libraries, functions as a Smad3/4 adaptor protein, plays critical roles in the proper control of Smad access to activating receptors involved in regulation of TGF- $\beta$ signaling [17-19]. Interestingly, ELF is a key suppressor of tumorigenesis [20,21]. Disruption of ELF expression by gene knockout was found to result in miscolocalization of Smad3 and Smad4, and disruption of TGF- $\beta$ signaling [22]. About half of mice with heterozygous deletion of ELF developed hepatocellular carcinoma, and $90 \%$ of $\mathrm{ELF}^{+/-} / \mathrm{Smad}^{4+/-}$ mice developed gastric cancer and other gastrointestinal cancers [23,24]. Loss of ELF may play a role in the malignant transformation of hepatic progenitor/stem cells [22]. However, the prognostic value of ELF for HCC is not well-known. Testing the combination of TGF- $\beta 1$ and ELF as a predictor for HCC prognosis is also merits study.

In the present study, we examined the pattern of expression of TGF- $\beta 1$ and ELF in HCC tumor tissues and normal tissues. Together with the known function, it is therefore of interest to investigate that TGF- $\beta 1$ and ELF protein are potential and reliable biomarker for predicting prognosis in HCC patients after hepatic resection, and prognostic accuracy of testing can be enhanced by their combination in the patients with HCC.

\section{Methods}

\section{Patients and tissue samples}

A total of 84 adult patients with HCC who underwent hepatic resection in the Department of Hepatobiliary Surgery, First Affiliated Hospital of Sun Yat-sen University between June 2007 and October 2009, were enrolled in this study, including 68 males and 16 females with an average age of 48 years (range 23 to 75 years). Written informed consent was obtained from all patients, and the study was conducted in accordance with the protocol approved by the Declaration of Helsinki and the guidelines of the Ethics Review Committee of First Affiliated Hospital of Sun Yat-sen University. In addition, normal liver tissues were collected from patients with cavernous hemangioma of liver or patients with intrahepatic stones.

The diagnosis of $\mathrm{HCC}$ met the criteria of the American Association for the study of Liver Disease [25]. The volume of liver resection and the surgical procedures were decided by tumor size, tumor location, and liver functional reserve based on a multidisciplinary team meeting every week. Tumor stages were classified according to the tumor-node-metastasis (TNM) system of the International Union Against Cancer by the American Joint Committee [26]. The histologic grade of tumor was assigned according to the Edmondson Steiner grading system [27]. Fresh HCC tissues and HCC adjacent tissues were collected within 30 minutes after resection. These tissues were fixed with $10 \%$ formalin and then embedded in paraffin.

\section{Immunohistochemical analysis}

The techniques have been described previously [16]. The sections were incubated with pre-diluted primary Rabbit polyclonal anti-ELF antibody (ab72239, Abcam, USA) at a dilution of 1:100, with Rabbit monoclonal anti-TGF- $\beta 1$ antibody (Y369, Bioworld, USA) at dilution of 1:100, at $4^{\circ} \mathrm{C}$ overnight. Negative controls were treated the same way, omitting the primary antibodies.

\section{Evaluation of immunohistochemical staining}

The immunohistochemical staining in the tissue was scored independently by 2 pathologists blinded to the clinical data, by applying a semiquantitative immunoreactivity score (IRS) reported elsewhere [28-30]. Category A documented the intensity of immunostaining as $0-3$ ( 0 , negative; 1 , weak; 2 , moderate; 3 , strong). Category $B$ documented the percentage of immunoreactive cells as 0 (less than 5\%), $1(6 \%-25 \%), 2(26 \%-50 \%), 3(51 \%-$ $75 \%)$, and $4(76 \%-100 \%)$. Multiplication of category A and $B$ resulted in an IRS ranging from 0 to 12 for each tumor or nontumor. Sections with a total score of 0 or 1 or 2 were defined as negative (-), score of 3 or 4 were defined as weakly positive $(+)$, score of 6 or 8 were defined as moderately positive $(++)$, score of 9 or 12 were defined as strongly positive $(+++)$. For categorical analyses, the immunoreactivity was graded as low level (total score $<=4$ ) or high level (total score $>4$ ).

\section{Follow-up}

The postoperative patients were followed up once a month during the first half year post-operatively and every 3 months thereafter. Serum AFP level and abdominal ultrasonography were done routinely during the postoperative review. Computed tomography (CT) was performed every 3 to 6 months together with chest radiographic examination. The endpoint of study was December 2013. Survival time was calculated from the date of surgery to the date of death or to the last 
Table 1 The expression of ELF in HCC

\begin{tabular}{llll}
\hline Group & $\mathbf{n}$ & \multicolumn{2}{l}{ Expression of ELF } \\
\cline { 3 - 4 } & & High & Low \\
\hline Normal liver tissues & 20 & $20(100.0 \%)$ & $0(0.0 \%)$ \\
Adjacent tissues* & 84 & $65(77.4 \%)$ & $19(22.6 \%)$ \\
HCC tissues*\# & 84 & $40(47.6 \%)$ & $44(52.4 \%)$ \\
\hline
\end{tabular}

*compared with Normal liver tissues, $P<0.001$ (by chi-square test).

${ }^{\#}$ compared with Adjacent tissues, $P<0.001$ (by chi-square test).

follow-up. Date of death was obtained from patient records or patients' families through follow-up telephone calls. Date of death for each case was double verified by local civil affairs department and public security department. The median follow-up period was 39 months (range 3 to 81 months).

Recurrence or metastasis was detected by imaging examination such as ultrasonography, contrast-enhanced ultrasonography, CT, magnetic resonance imaging (MRI), hepatic arterial angiography, or positron emission tomography -CT (PET-CT). Isolated increases in serum AFP were not regarded as recurrent events. Once tumor recurrence was verified, patients received the appropriate further treatments, including repeat liver resection, radiofrequency
Table 2 The expression of TGF- $\beta 1$ in HCC

\begin{tabular}{llll}
\hline Group & $\mathbf{n}$ & \multicolumn{2}{l}{ Expression of TGF- $\boldsymbol{\beta} \mathbf{1}$} \\
\cline { 3 - 4 } & & High & Low \\
\hline Normal liver tissues & 20 & $0(0.0 \%)$ & $20(100.0 \%)$ \\
Adjacent tissues* $^{*}$ HCC tissues* $^{*}$ & 84 & $39(46.4 \%)$ & $45(53.6 \%)$ \\
\hline
\end{tabular}

${ }^{*}$ compared with Normal liver tissues, $P<0.001$ (by chi-square test).

ablation, percutaneous ethanol injection, chemoembolization, and/or molecular targeting therapy by sorafenib.

\section{Statistical analysis}

Statistical analyses were carried out using the SPSS v 13. 0 software (Chicago, IL, USA). The Wilcoxon W rank sum test and chi-square test was used to compare qualitative variables. Spearman correlation was used to investigate the correlation between ELF and TGF- $\beta 1$ expression. Survival curves were calculated using the Kaplan-Meier method and were compared by a log-rank test, illustrated by survival plots. The Cox proportional hazards model was used to determine the independent risk factors associated with prognosis. $P<0.05$ was considered statistically significant.

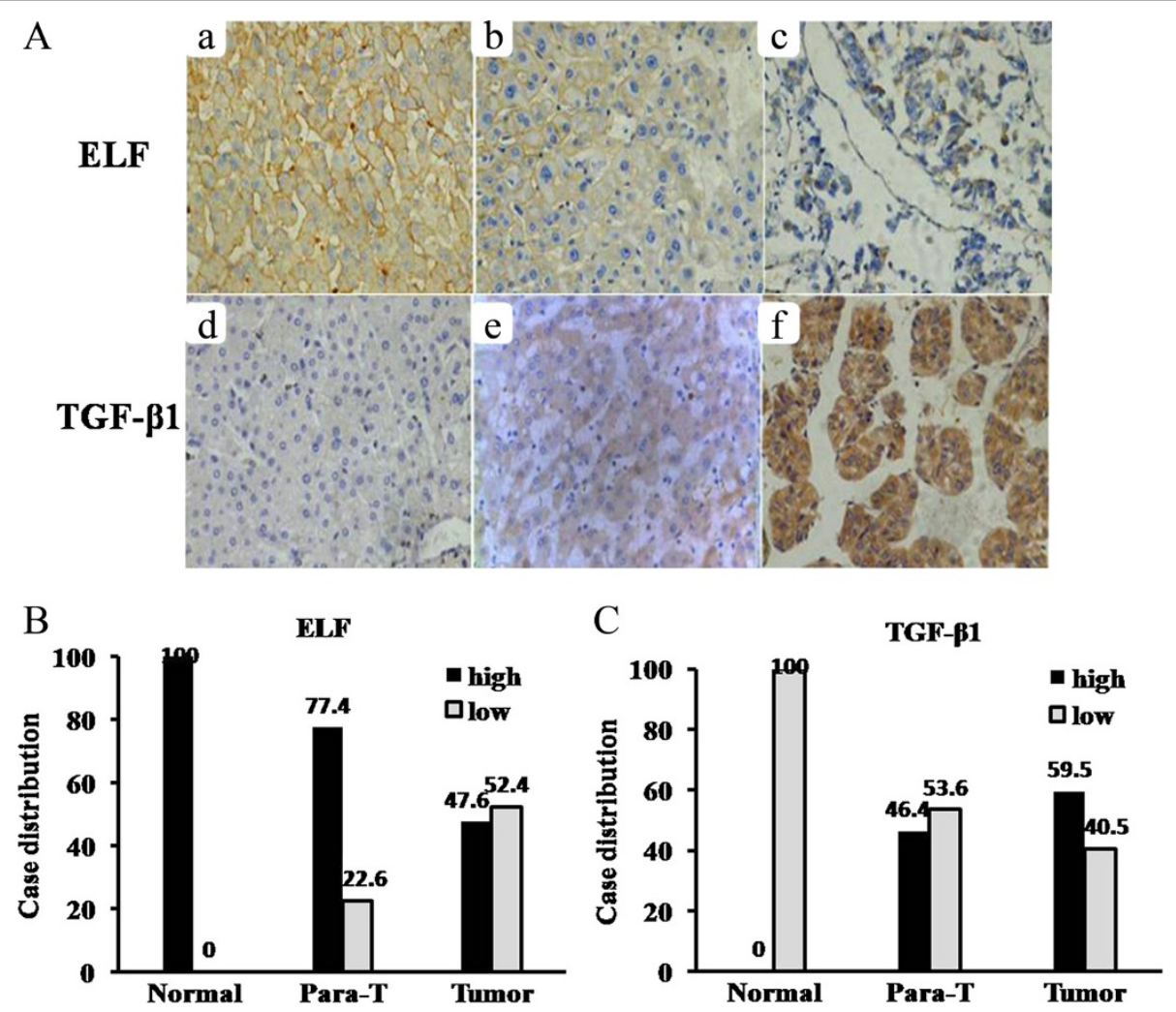

Figure 1 Expression of ELF and TGF- $\beta 1$ protein. (A) Immunohistochemical staining in different tissues is shown. Normal liver tissues (Aa and Ad), HCC adjacent tissues (Ab and Ae), HCC tissues (AC and Af) (original magnification $\times 400$ ). (B) and (C) Case distribution of ELF/TGF- $\beta 1$ expression in normal liver tissues (Normal), HCC adjacent tissues (Para-T) and HCC tissue (Tumor). 
Table 3 Correlation between the clinicopathological characteristics and expression of ELF and TGF- $\beta 1$ in the 84 HCC patients

\begin{tabular}{|c|c|c|c|c|c|c|c|}
\hline \multirow[t]{2}{*}{ Variables } & \multirow[t]{2}{*}{ Cases } & \multicolumn{2}{|c|}{ ELF expression } & \multirow[t]{2}{*}{$P$ value } & \multicolumn{2}{|c|}{ TGF- $\beta 1$ expression } & \multirow[t]{2}{*}{$P$ value } \\
\hline & & Low & High & & Low & High & \\
\hline \multicolumn{8}{|l|}{ Age(yrs) } \\
\hline$>=60$ & 16 & $7(43.8 \%)$ & $9(56.2 \%)$ & 0.442 & $9(54.4 \%)$ & $7(54.4 \%)$ & 0.325 \\
\hline$<60$ & 68 & $37(54.4 \%)$ & $31(45.6 \%)$ & & $29(42.6 \%)$ & $39(57.4 \%)$ & \\
\hline \multicolumn{8}{|l|}{ Sex } \\
\hline Male & 68 & $37(54.4 \%)$ & $31(45.6 \%)$ & 0.44 & 27(39.7\%) & $41(60.3 \%)$ & 0.77 \\
\hline Female & 16 & $7(43.8 \%)$ & $9(56.2 \%)$ & & $7(43.8 \%)$ & $9(56.2 \%)$ & \\
\hline \multicolumn{8}{|c|}{ HCC family history } \\
\hline Yes & 6 & $2(33.3 \%)$ & $4(66.7 \%)$ & 0.83 & $3(50.0 \%)$ & $3(50.0 \%)$ & 0.95 \\
\hline No & 78 & $42(53.8 \%)$ & $36(46.2 \%)$ & & $31(39.7 \%)$ & $47(60.3 \%)$ & \\
\hline \multicolumn{8}{|l|}{$\mathrm{HbsAg}$} \\
\hline Positive & 72 & $41(56.9 \%)$ & $31(43.1 \%)$ & 0.04 & $29(40.3 \%)$ & $43(59.7 \%)$ & 0.93 \\
\hline Negative & 12 & $3(25.0 \%)$ & $9(75.0 \%)$ & & $5(41.7 \%)$ & $7(58.3 \%)$ & \\
\hline \multicolumn{8}{|l|}{$\operatorname{ALT}(U / L)$} \\
\hline$\geq 80$ & 9 & $3(33.3 \%)$ & $6(66.7 \%)$ & 0.39 & $1(11.1 \%)$ & 8(88.9\%) & 0.12 \\
\hline$<80$ & 75 & $41(54.7 \%)$ & $34(45.3 \%)$ & & $33(44.0 \%)$ & $42(56.0 \%)$ & \\
\hline \multicolumn{8}{|l|}{$\operatorname{PLT}\left(\times 10^{9}\right)$} \\
\hline$>100$ & 74 & $41(55.4 \%)$ & $33(44.6 \%)$ & 0.24 & $28(37.8 \%)$ & $46(62.2 \%)$ & 0.32 \\
\hline$\leq 100$ & 10 & $3(30.0 \%)$ & 7(70.0\%) & & $6(60.0 \%)$ & $4(40.0 \%)$ & \\
\hline \multicolumn{8}{|l|}{ Cirrhosis } \\
\hline Yes & 64 & $32(50.0 \%)$ & $32(50.0 \%)$ & 0.43 & $27(42.2 \%)$ & $37(57.8 \%)$ & 0.57 \\
\hline No & 20 & $12(60.0 \%)$ & $8(40.0 \%)$ & & 7(35.0\%) & $13(65.0 \%)$ & \\
\hline \multicolumn{8}{|l|}{ AFP(ug/L) } \\
\hline$\geq 20$ & 48 & 28(58.3\%) & $20(41.7 \%)$ & 0.21 & 19(39.6\%) & $29(60.4 \%)$ & 0.85 \\
\hline$<20$ & 36 & 16(44.4\%) & 20(55.6\%) & & 15(41.7\%) & $21(58.3 \%)$ & \\
\hline \multicolumn{8}{|c|}{ Tumor size $(\mathrm{cm})$} \\
\hline$\geq 5$ & 50 & $32(64.0 \%)$ & 18(36.0\%) & 0.01 & $13(26.0 \%)$ & $37(74.0 \%)$ & 0.001 \\
\hline$<5$ & 34 & 12(35.3\%) & $22(64.7 \%)$ & & $21(61.8 \%)$ & 13(38.2\%) & \\
\hline \multicolumn{8}{|c|}{ Tumor number } \\
\hline Single & 62 & $26(41.9 \%)$ & $36(58.1 \%)$ & 0.001 & $31(50.0 \%)$ & $31(50.0 \%)$ & 0.003 \\
\hline Multiple & 22 & 18(81.8\%) & $4(18.2 \%)$ & & $3(13.6 \%)$ & 19(86.4\%) & \\
\hline \multicolumn{8}{|c|}{ Differentiation } \\
\hline$|-| \mid$ & 62 & $31(50.0 \%)$ & $31(50.0 \%)$ & 0.46 & $27(43.5 \%)$ & $35(56.5 \%)$ & 0.34 \\
\hline III-IV & 22 & 13(59.1\%) & $9(40.9 \%)$ & & $7(31.8 \%)$ & $15(68.2 \%)$ & \\
\hline \multicolumn{8}{|l|}{ TNM stage } \\
\hline$|-| \mid$ & 55 & $24(43.6 \%)$ & $31(56.4 \%)$ & 0.03 & 29(52.7\%) & $26(47.3 \%)$ & 0.002 \\
\hline III-IV & 29 & $20(69.0 \%)$ & $9(31.0 \%)$ & & $5(17.2 \%)$ & $24(82.8 \%)$ & \\
\hline \multicolumn{8}{|l|}{ PVIT } \\
\hline Yes & 11 & $8(72.7 \%)$ & $3(27.3 \%)$ & 0.15 & $2(18.2 \%)$ & $9(81.8 \%)$ & 0.11 \\
\hline No & 73 & $36(49.3 \%)$ & $37(50.7 \%)$ & & $32(43.8 \%)$ & $41(56.2 \%)$ & \\
\hline \multicolumn{8}{|c|}{ Tumor encapsulation } \\
\hline Complete & 64 & $30(46.9 \%)$ & $34(53.1 \%)$ & 0.07 & $29(45.3 \%)$ & $35(54.7 \%)$ & 0.11 \\
\hline None & 20 & 14(70.0\%) & $6(30.0 \%)$ & & $5(25.0 \%)$ & $15(75.0 \%)$ & \\
\hline
\end{tabular}


Table 3 Correlation between the clinicopathological characteristics and expression of ELF and TGF- $\beta 1$ in the 84 HCC patients (Continued)

\begin{tabular}{|c|c|c|c|c|c|c|c|}
\hline \multicolumn{8}{|c|}{ Recurrence } \\
\hline Yes & 56 & $39(69.6 \%)$ & $17(30.4 \%)$ & $<0.001$ & $12(21.4 \%)$ & $44(78.6 \%)$ & $<0.001$ \\
\hline No & 28 & $5(17.9 \%)$ & $23(82.1 \%)$ & & $22(78.6 \%)$ & $6(21.4 \%)$ & \\
\hline \multicolumn{8}{|c|}{ Complication } \\
\hline No & 73 & $41(56.2 \%)$ & $32(43.8 \%)$ & 0.07 & $31(42.5 \%)$ & $42(57.5 \%)$ & 0.34 \\
\hline Yes & 11 & $3(27.3 \%)$ & 8(72.7\%) & & $3(27.3 \%)$ & $8(72.7 \%)$ & \\
\hline
\end{tabular}

AFP, Alpha-fetoprotein; HBsAg, hepatitis B surface antigen; PLT, platelet; PVTT, portal vein tumor thrombi.

\section{Results}

The low expression of ELF and the high expression of TGF- $\beta 1$ in HCC tissues

Using immunohistochemical staining, we examine expression of ELF and TGF- $\beta 1$ on 20 normal liver tissues, 84 HCC samples and adjacent tissues. All normal liver tissues expressed high level of ELF (20/20). In HCC adjacent tissues, there was a $77.4 \%$ high expression rate for ELF (65/84). However, the ELF high expression rate declined to $47.6 \%(40 / 84)$ in HCC tissues. There was significant difference among the groups examined $(P<0.001)$ (Table 1 , Figure 1A, B). On the contrary, the expression rate of TGF- $\beta 1$ in HCC tissues $(59.5 \%, 50 / 84)$ was significantly higher than that in the normal liver tissues $(0,0 / 20, P<0.001)$, but not in $\mathrm{HCC}$ adjacent tissues $(46.4 \%, 39 / 84, P=0.089$, Table 2, Figure $1 \mathrm{~A}, \mathrm{C}$ ). These results suggested that there was the low expression of ELF and high expression of TGF- $\beta 1$ in HCC tissues.

\section{Correlation between TGF- $\beta 1 /$ ELF expression and 16 clinico-pathologic characteristics in HCC}

In order to further understand the prognostic value of TGF- $\beta 1 / E L F$ expression for HCC after resection, the relationships between the expression of these proteins and 16 clinico-pathologic characteristics, such as age, gender, HCC family, HBsAg, ALT, AFP, cirrhosis, ascites, PVTT, tumor size, tumor number, tumor differentiation, tumor encapsulation, TNM stage, recurrence and complication, were analyzed. The expression level of ELF was negatively correlated with $\operatorname{HBsAg}(P=0.04)$, tumor size $(P=0.010)$, tumor number $(P=0.001)$, TNM stage $(P=0.027)$ and recurrence $(P<0.001)$. As predicted,

Table 4 The correlationship between ELF and TGF- $\beta 1$ in HCC

\begin{tabular}{|c|c|c|c|c|c|}
\hline \multirow[t]{2}{*}{$E L F$} & \multicolumn{3}{|c|}{$T G F-\beta 1$} & \multirow[t]{2}{*}{$r$} & \multirow[t]{2}{*}{$P$ value } \\
\hline & +++ & ++ & $-\sim+$ & & \\
\hline+++ & 7 & 4 & 12 & -0.271 & 0.013 \\
\hline++ & 4 & 1 & 12 & & \\
\hline$-\sim+$ & 20 & 14 & 10 & & \\
\hline
\end{tabular}

TGF- $\beta 1$ expression was positively associated with the tumor size $(P=0.001)$, tumor number $(P=0.003)$, TNM stage $(P=0.002)$ and recurrence $(P<0.001)$, too (Table 3$)$. In addition, we found the significant negative correlation between ELF and TGF- $\beta 1$ expression patterns by using Spearman correlation $(r=-0.271, P=0.013$, Table 4).

\section{Independent prognostic factors of HCC}

To further identify the risk factors linked to postoperative Disease Free Survival (DFS) and Overall Survival (OS), ELF, TGF- $\beta 1$ and 16 clinicopathologic factors were evaluated by univariate analysis and the Cox regression model. The univariate analysis showed that the significant prognostic factors for DFS of HCC were tumor number, portal vein tumor thrombus (PVTT), tumor encapsulation, TNM stage, ELF expression, and TGF- $\beta 1$ expression. Similarly, the analysis showed that the significant factors for OS of HCC were tumor number, PVTT, tumor size, resection margin, tumor differentiation, TNM stage, ELF expression, and TGF- $\beta 1$ expression (all $P<0.05$ ). Using the Cox regression multivariate analysis, we found that PVTT, ELF expression, and TGF- $\beta 1$ expression were the significant independent related factors for DFS (all $P<0.05$ ), in addition, tumor differentiation $(P=0.029)$, PVTT $(P=0.011)$, ELF expression $(P=0.042)$ and TGF- $\beta 1$ expression $(P<0.001)$ were the significant independent related factors for OS (Tables 5 and 6).

\section{Low expression of ELF and high expression of TGF- $\beta 1$} predict HCC patients' poor prognosis

Firstly, we divided 84 patients with HCC into 2 groups according to their ELF expression profiles: the lowexpression group $(\mathrm{n}=44)$ and the high-expression group $(\mathrm{n}=40)$. Using the Kaplan-Meier method to analyze patients' survival, we found that the 1-, 3- and 5-year DFS rates of the high-expression ELF group were remarkably higher than the low-expression group $(75.0 \%, 60.0 \%$ and $57.5 \%$ vs $25.0 \%, 15.9 \%$ and $10.2 \%$, respectively, $P<0.001$ ) (Figure 2A), while the 1-, 3- and 5-year OS rates of the high-expression ELF group were significantly higher than those of the low-expression group (90.0\%, 72.5\% 
Table 5 Prognostic factors for DFS and OS by univariate analysis

\begin{tabular}{|c|c|c|c|c|c|c|c|c|c|}
\hline \multirow[t]{2}{*}{ Variables } & \multirow[t]{2}{*}{$n$} & \multicolumn{3}{|l|}{ DFS } & \multirow[t]{2}{*}{$P$} & \multicolumn{3}{|l|}{ os } & \multirow[t]{2}{*}{$P$} \\
\hline & & $1-\mathrm{yr}$ & 3-yrs & 5-yrs & & $1-y r$ & 3-yrs & 5-yrs & \\
\hline \multicolumn{10}{|l|}{ Sex } \\
\hline Male & 68 & $54.4 \%$ & $36.8 \%$ & $30.7 \%$ & 0.53 & $79.4 \%$ & $50.0 \%$ & $41.2 \%$ & 0.48 \\
\hline Female & 16 & $56.3 \%$ & $37.5 \%$ & $37.5 \%$ & & $87.5 \%$ & $56.3 \%$ & $50.0 \%$ & \\
\hline \multicolumn{10}{|l|}{ Age(yrs) } \\
\hline$<60$ & 68 & $45.6 \%$ & $32.4 \%$ & $29.3 \%$ & 0.15 & $82.4 \%$ & $48.5 \%$ & $39.7 \%$ & 0.39 \\
\hline$\geq 60$ & 16 & $62.5 \%$ & $56.3 \%$ & $42.2 \%$ & & $75.0 \%$ & $62.5 \%$ & $56.3 \%$ & \\
\hline \multicolumn{10}{|c|}{ HCC family history } \\
\hline Yes & 6 & $50.0 \%$ & $33.3 \%$ & $16.7 \%$ & 0.57 & $83.3 \%$ & $50.0 \%$ & $50.0 \%$ & 0.63 \\
\hline No & 78 & $48.7 \%$ & $37.2 \%$ & $33.3 \%$ & & $79.5 \%$ & $51.3 \%$ & $42.3 \%$ & \\
\hline \multicolumn{10}{|l|}{$\operatorname{PLT}\left(\times 10^{9}\right)$} \\
\hline$<100$ & 10 & $80.0 \%$ & $60.0 \%$ & $60.0 \%$ & 0.07 & $100.0 \%$ & $80.0 \%$ & $70.0 \%$ & 0.08 \\
\hline$\geq 100$ & 74 & $44.6 \%$ & $33.8 \%$ & $28.2 \%$ & & $78.4 \%$ & $47.3 \%$ & $39.2 \%$ & \\
\hline \multicolumn{10}{|l|}{ HBsAg } \\
\hline Positive & 72 & $47.2 \%$ & $38.9 \%$ & $33.3 \%$ & 0.90 & $79.2 \%$ & $50.0 \%$ & $44.4 \%$ & 0.88 \\
\hline Negative & 12 & $58.3 \%$ & $25.0 \%$ & $25.0 \%$ & & $91.7 \%$ & $58.3 \%$ & $33.3 \%$ & \\
\hline \multicolumn{10}{|l|}{ AFP( $\mu \mathrm{g} / \mathrm{L})$} \\
\hline$<20$ & 36 & $52.8 \%$ & $38.9 \%$ & $38.9 \%$ & 0.34 & $83.3 \%$ & $50.0 \%$ & $44.4 \%$ & 0.75 \\
\hline$\geq 20$ & 48 & $45.8 \%$ & $35.4 \%$ & $26.7 \%$ & & $79.2 \%$ & $52.1 \%$ & $41.7 \%$ & \\
\hline \multicolumn{10}{|l|}{ Ascites } \\
\hline No & 68 & $52.9 \%$ & $39.7 \%$ & $34.1 \%$ & 0.14 & $83.8 \%$ & $51.5 \%$ & $44.1 \%$ & 0.55 \\
\hline Yes & 16 & $31.3 \%$ & $25.0 \%$ & $25.0 \%$ & & $68.8 \%$ & $50.0 \%$ & $37.5 \%$ & \\
\hline \multicolumn{10}{|l|}{ Cirrhosis } \\
\hline No & 24 & $45.0 \%$ & $35.0 \%$ & $30.0 \%$ & 0.78 & $95.0 \%$ & $60.0 \%$ & $45.0 \%$ & 0.49 \\
\hline Yes & 60 & $50.0 \%$ & $37.5 \%$ & $32.9 \%$ & & $76.6 \%$ & $48.4 \%$ & $42.2 \%$ & \\
\hline \multicolumn{10}{|c|}{ Tumor number } \\
\hline Single & 62 & $59.7 \%$ & $43.5 \%$ & $36.9 \%$ & 0.003 & $85.5 \%$ & $61.3 \%$ & $51.6 \%$ & $<0.001$ \\
\hline Multiple & 22 & $18.2 \%$ & $18.2 \%$ & $18.2 \%$ & & $68.2 \%$ & $22.7 \%$ & $18.2 \%$ & \\
\hline \multicolumn{10}{|l|}{ PVTT } \\
\hline No & 73 & $54.8 \%$ & $41.1 \%$ & $35.4 \%$ & $<0.001$ & $87.7 \%$ & $56.2 \%$ & $47.9 \%$ & $<0.001$ \\
\hline Yes & 11 & $9.1 \%$ & $9.1 \%$ & $9.1 \%$ & & $36.4 \%$ & $18.2 \%$ & $9.1 \%$ & \\
\hline \multicolumn{10}{|c|}{ Tumor size $(\mathrm{cm})$} \\
\hline$<5$ & 34 & $64.7 \%$ & $47.1 \%$ & $39.2 \%$ & 0.05 & $97.1 \%$ & $67.6 \%$ & $52.9 \%$ & 0.04 \\
\hline$\geq 5$ & 50 & $38.0 \%$ & $30.0 \%$ & $28.0 \%$ & & $70.0 \%$ & $40.0 \%$ & $36.0 \%$ & \\
\hline \multicolumn{10}{|c|}{ Tumor encapsulation } \\
\hline None & 20 & $30.0 \%$ & $25.0 \%$ & $15.0 \%$ & 0.01 & $60.0 \%$ & $45.0 \%$ & $30.0 \%$ & 0.08 \\
\hline Complete & 64 & $54.7 \%$ & $40.6 \%$ & $37.7 \%$ & & $87.5 \%$ & $53.1 \%$ & $46.9 \%$ & \\
\hline \multicolumn{10}{|c|}{ Resection margin } \\
\hline$<2 \mathrm{~cm}$ & 45 & $40.0 \%$ & $26.7 \%$ & $24.4 \%$ & 0.07 & $80.0 \%$ & $40.0 \%$ & $28.9 \%$ & 0.01 \\
\hline$\geq 2 \mathrm{~cm}$ & 39 & $59.0 \%$ & $48.7 \%$ & $39.6 \%$ & & $82.1 \%$ & $64.1 \%$ & $59.0 \%$ & \\
\hline \multicolumn{10}{|l|}{ Complication } \\
\hline No & 73 & $49.3 \%$ & $38.4 \%$ & $33.1 \%$ & 0.37 & $84.9 \%$ & $53.4 \%$ & $45.2 \%$ & 0.10 \\
\hline Yes & 11 & $45.5 \%$ & $27.3 \%$ & $27.3 \%$ & & $54.5 \%$ & $36.4 \%$ & $27.3 \%$ & \\
\hline
\end{tabular}

Tumor differetiation 
Table 5 Prognostic factors for DFS and OS by univariate analysis (Continued)

\begin{tabular}{|c|c|c|c|c|c|c|c|c|c|}
\hline$|-| \mid$ & 62 & $54.8 \%$ & $41.9 \%$ & $35.1 \%$ & 0.16 & $85.5 \%$ & $56.5 \%$ & $48.4 \%$ & 0.04 \\
\hline III-IV & 22 & $31.8 \%$ & $22.7 \%$ & $22.7 \%$ & & $68.2 \%$ & $36.4 \%$ & $27.3 \%$ & \\
\hline \multicolumn{10}{|c|}{ TNM stage } \\
\hline I-H & 55 & $60.0 \%$ & $43.6 \%$ & $38.0 \%$ & 0.01 & $90.9 \%$ & $60 \%$ & $52.7 \%$ & 0.001 \\
\hline III-IV & 29 & $27.6 \%$ & $24.1 \%$ & $20.7 \%$ & & $62.1 \%$ & $34.5 \%$ & $24.1 \%$ & \\
\hline \multicolumn{10}{|c|}{ ELF expression } \\
\hline Low & 44 & $25.0 \%$ & $15.9 \%$ & $10.2 \%$ & $<0.001$ & $72.7 \%$ & $31.8 \%$ & $23.7 \%$ & $<0.001$ \\
\hline High & 40 & $75.0 \%$ & $60.0 \%$ & $57.5 \%$ & & $90.0 \%$ & $72.5 \%$ & $65.0 \%$ & \\
\hline \multicolumn{10}{|c|}{ TGF $\beta 1$ expression } \\
\hline Low & 34 & $79.4 \%$ & $73.5 \%$ & $62.0 \%$ & $<0.001$ & $94.1 \%$ & $85.3 \%$ & $76.5 \%$ & $<0.001$ \\
\hline High & 50 & $28.0 \%$ & $12.0 \%$ & $12.0 \%$ & & $72.0 \%$ & $28.0 \%$ & $20.0 \%$ & \\
\hline
\end{tabular}

AFP, Alpha-fetoprotein; HBsAg, hepatitis B surface antigen; PLT, platelet; PVTT, portal vein tumor thrombi.

and $65.0 \%$ vs $72.7 \%, 31.8 \%$ and $23.7 \%$, respectively, $P<0.001$ ) (Figure 2B). Our findings therefore indicated that ELF expression levels were positively correlated with patients' DFS and OS.

Similarly, Two groups were divided from $84 \mathrm{HCC}$ patients according to their TGF- $\beta 1$ expression profiles: the low-expression group $(\mathrm{n}=34)$ and the high-expression group $(n=50)$. We observed that the 1 -, 3- and 5-year DFS rates of the low-expression TGF- $\beta 1$ group were markedly higher than the high-expression group $(79.4 \%$, $73.5 \%$ and $62.0 \%$ vs $28.0 \%, 12.0 \%$ and $12.0 \%$, respectively, $P<0.001$ ) (Figure 3A). Also, the 1-, 3- and 5-year OS rates of the low-expression TGF- $\beta 1$ group were significantly higher than those of the high-expression group (94.1\%, $85.3 \%$ and $76.5 \%$ vs $72.0 \%, 28.0 \%$ and $20.0 \%$, respectively, $P<0.001$ ) (Figure $3 \mathrm{~B}$ ). These data suggested that TGF- $\beta 1$ expression levels were negatively correlated with patients' DFS and OS.

The combination of TGF- $\beta 1$ and ELF exhibits the improved prognostic accuracy for HCC

To analyze the prognostic value of combining TGF- $\beta 1$ and ELF levels for HCC, we divided patients into the following four groups, such as: TGF- $\beta 1$ high expressionELF high expression group, TGF- $\beta 1$ low expression- ELF high expression group, TGF- $\beta 1$ high expression - ELF low expression group, TGF- $\beta 1$ low expression- ELF low expression group. The data showed that the TGF- $\beta 1$ low expression- ELF high expression group had the best DFS and OS rates, TGF- $\beta 1$ low expression- ELF low expression group was the second best, the next was TGF- $\beta 1$ high expression- ELF high expression group, whereas TGF- $\beta 1$ high expression- ELF low expression group had the worst prognosis.

The 1-, 3- and 5-year DFS rates of TGF- $\beta 1$ low expression- ELF high expression group (87.5\%, 79.2\% and $75.0 \%$ ) were significantly higher than those of TGF- $\beta 1$ high expression- ELF high expression group $(56.3 \%, 31.3 \%$ and $31.3 \%, P=0.003)$ and TGF- $\beta 1$ high expression- ELF low expression group (26.5\%, 2.9\% and $2.9 \%, P<0.001)$. The 1 -, 3 - and 5 -year OS rates of TGF- $\beta 1$ low expression- ELF high expression group (95.8\%, 91.7\% and 83.3\%) were also significantly higher than those of TGF- $\beta 1$ high expression- ELF high expression group (81.3\%, $43.8 \%$ and $37.5 \%, P=0.001)$ and TGF$\beta 1$ high expression- ELF low expression group (67.6\%, $20.6 \%$ and $11.8 \%, P<0.001$ ) (Figure $4 \mathrm{~A}$ and $\mathrm{B}$ ).

Furthermore, we found that the 1-, 3- and 5-year DFS rates of TGF- $\beta 1$ high expression-ELF low expression (26.5\%, 2.9\% and 2.9\%) were remarkably lower than TGF$\beta 1$ high expression- ELF high expression (56.3\%, 31.3\% and $31.3 \%, P=0.002$ ) and TGF- $\beta 1$ low expression-ELF

Table 6 Prognostic factors for disease-free and overall survival by the multivariate Cox proportional hazards regression model

\begin{tabular}{|c|c|c|c|c|c|c|}
\hline \multirow[t]{2}{*}{ Variables } & \multicolumn{3}{|l|}{ DFS } & \multicolumn{3}{|l|}{ OS } \\
\hline & $\mathrm{HR}$ & $95 \% \mathrm{Cl}$ & $P$ & $\mathrm{HR}$ & $95 \% \mathrm{Cl}$ & $P$ \\
\hline Tumor differentiation & & & & 0.498 & $0.266-0.932$ & 0.029 \\
\hline PVTT & 0.405 & $0.199-0.824$ & 0.013 & 0.398 & $0.195-0.812$ & 0.011 \\
\hline ELF expression & 2.135 & $1.115-4.088$ & 0.022 & 1.989 & $1.024-3.862$ & 0.042 \\
\hline TGF $\beta 1$ expression & 0.219 & 0.099-0.486 & $<0.001$ & 0.210 & $0.093-0.474$ & $<0.001$ \\
\hline
\end{tabular}

$\mathrm{HR}$, hazard ratio; $\mathrm{Cl}$, confidence interval; PVTT, portal vein tumor thrombi. 

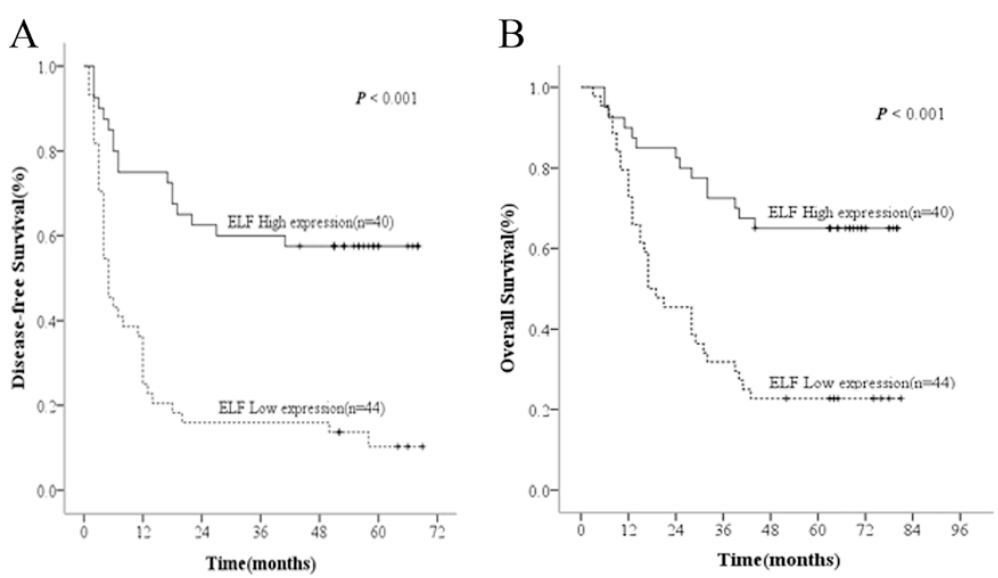

Figure 2 Kaplan-Meier curves are shown for time to disease recurrence (A) and overall survival (B) among patients with high or low intratumoral ELF expression.

low expression $(60.0 \%, 60.0 \%$ and $37.5 \%, P=0.002)$. Also, the 1-, 3- and 5-year OS rates of TGF- $\beta 1$ high expressionELF low expression $(67.6 \%, 20.6 \%$ and $11.8 \%$ ) were markedly lower than TGF- $\beta 1$ low expression-ELF low expression group $(90.0 \%, 70.0 \%$ and $60.0 \%, P=0.003)$. However, there was no significant difference of OS rates between TGF- $\beta 1$ high expression-ELF low expression and TGF- $\beta 1$ high expression- ELF high expression $(67.6 \%, 20.6 \%$ and $11.8 \%$ vs $81.3 \%, 43.8 \%$ and $37.5 \%$, respectively, $P=0.058$ ). We also found no significant difference of DFS and OS rates between TGF- $\beta 1$ low expression-ELF high expression group and TGF- $\beta 1$ low expression- ELF low expression group, or between TGF$\beta 1$ low expression-ELF low expression group and TGF$\beta 1$ high expression-ELF high expression group (Figure 4A and $\mathrm{B})$. Collecting, the results indicated that the combination of TGF- $\beta 1$ elevation and ELF reduction in HCC tissues appears to be predictive of the poorest prognosis.

\section{Discussion}

In the past few decades, great efforts have been made to explore the molecular mechanism of HCC to identify biomarkers for prediction and to develop effective treatments. In this study, we focused on investigating the prognostic significance of TGF- $\beta 1$ and ELF, in particular their combination, for HCC. Our first finding showed that the TGF- $\beta 1$ protein was upregulated in human HCC tissues and no normal liver tissues with strong cytoplasmic TGF- $\beta 1$ protein immunostaining. The results were consistent with our previous study that the low-expression of TGF- $\beta 1$ in normal rat liver tissues and the high-expression of TGF- $\beta 1$ in rat HCC tissues [16]. Like others reports [31,32]. We also found the positive correlation between TGF- $\beta 1$ and several clinicopathological characteristics: tumor size, tumor number, TNM stage and recurrence. A shorter post-operative survival of HCC patients with high level of TGF- $\beta 1$ had been
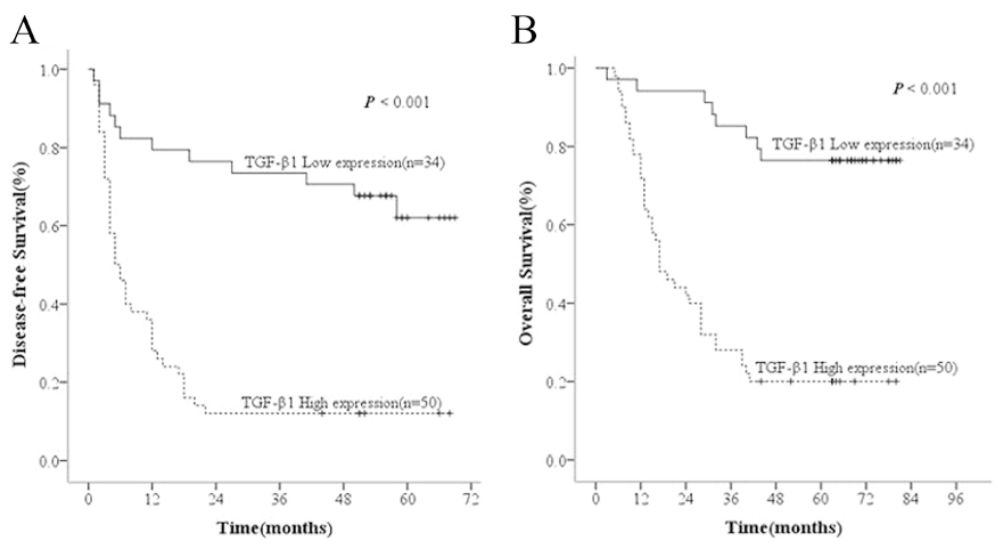

Figure 3 Kaplan-Meier curves are shown for time to disease recurrence (A) and overall survival (B) among patients with high or low intratumoral TGF- $\beta 1$ expression. 

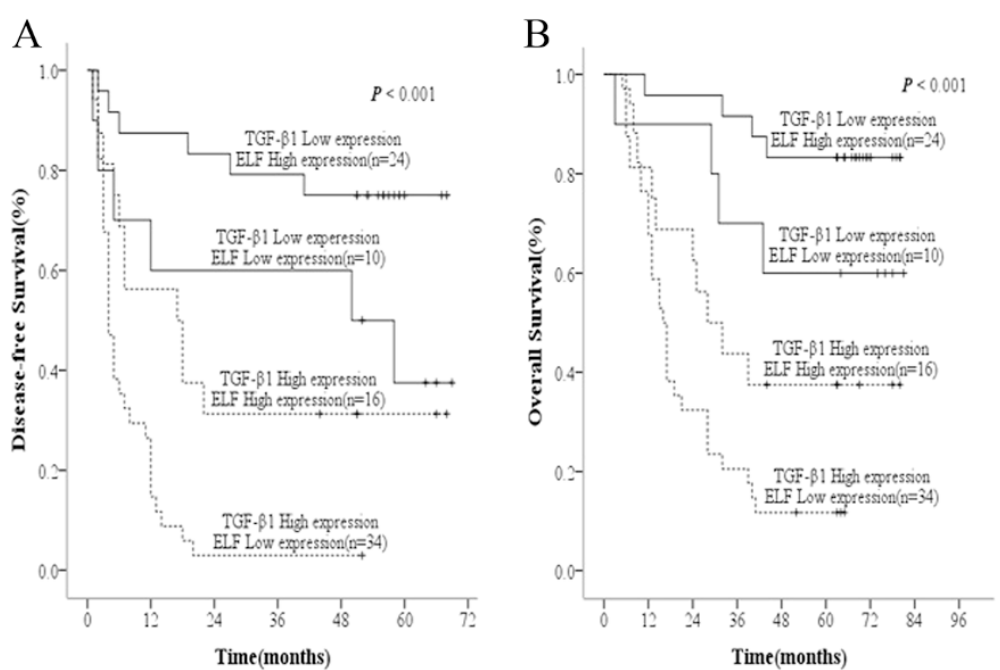

Figure 4 The combination of ELF and TGF- $\beta 1$ was found to enhance prognostic accuracy for HCC. Disease-free survival curves (A) and overall survival curves (B)

documented in this study. The 1-, 3- and 5-year DFS rates and OS rates of HCC patients with high level of TGF- $\beta 1$ were markedly lower than the low-expression group.

Why do the functions of TGF- $\beta$ switch from tumor suppression to tumor promotion? Mishra L et al. indicated that proper control of TGF- $\beta$ signaling tumor suppressor function requires an additional adaptor protein, ELF. Research from that group indicated that disruption of ELF expression results in miscolocalization of Smad3 and Smad4, then disruption of TGF- $\beta$ signaling, allowing normal cells to escape from the regulation of proliferation in carcinogenesis [21,33-36]. However, it was not reported if ELF expression level correlated with survival of HCC patients.

It is therefore of interest to investigate the expression and clinical significance of ELF in patients with HCC. We found that ELF was lost or underexpressed in the majority of HCC tissues, and that a high level of ELF expression predicted a favorable DFS rate and OS rate for HCC patients. Our data showed that the expression of ELF negatively correlated with $\mathrm{HbsAg}$, tumor size, tumor number, TNM and recurrence. The 1-, 3- and 5year DFS rates of HCC patients with the high level of ELF expression were remarkably higher than those of HCC patinets with the low levels. Similarly, the 1-, 3and 5-year OS rates of HCC patients with the high level of ELF expression were significantly higher than those of HCC patients with the low levels. These data were consistent with previous studies, which showed that significant ELF reduction was found in HCC, gastric cancer and lung cancer [33-36].

Further, we studied the correlation between ELF and TGF- $\beta 1$ in HCC patients, and demonstrated their significant negative correlation. Then we used univariate analysis and the Cox regression mode to study the role of ELF and TGF- $\beta 1$ on HCC, finding that the expression of ELF and TGF- $\beta 1$ were both significant and independent prognostic factors for DFS or OS of HCC. These data further verified that ELF and TGF- $\beta 1$ were important and promising candidate tumor biomarker for predicting the prognosis of patients with $\mathrm{HCC}$, and we hypothesized if combination of ELF and TGF- $\beta 1$ could give us a more sensitive way to predict $\mathrm{HCC}$ patients' outcome.

It is widely understood that a combination of multiple markers might yield more information for predicting clinical outcome of HCC patients [37]. Elevation of TGF- $\beta 1$ or reduction of ELF in HCC tissues appears to be predictive of a poor prognosis. The combination of TGF- $\beta 1$ and ELF expression were therefore used as a predictor of clinical outcome. The results indicated that their combination has a better prognostic value compared with either one alone. For example, those patients with low ELF expression and high TGF- $\beta 1$ expression had the poorest OS and DFS rates, whereas those patients with high ELF expression and low TGF- $\beta 1$ expression had the most favorable OS and DFS rates. The second best prognosis belonged to these patients with low ELF expression and low TGF- $\beta 1$ expression. In addition, we found that high level of ELF could partially rescue TGF- $\beta 1$ related tumor promotion, but TGF$\beta 1$ still was the more important factor for prognosis of patient with HCC.

\section{Conclusions}

Our study determined that loss or reduction of ELF and elevation of TGF- $\beta 1$ was correlated with disease 
progression and metastasis in patients with HCC. And the most interesting finding was that the predictive range of ELF levels combined with TGF- $\beta 1$ expression was more sensitive than that of either ELF or TGF- $\beta 1$ alone with regard to $\mathrm{OS}$ and cumulative disease recurrence in patients with HCC. From a diagnostic viewpoint, our results suggest that the detection of tumor ELF alone or the combined evaluation of ELF/ TGF- $\beta 1$ levels could be used as a new prognostic marker in patients with HCC. However, the exact mechanisms of ELF and TGF- $\beta 1$ expression regulation and function in HCC should been elucidated further. In the future, ELF might be used as potentially powerful target for treatment of HCC through enhancing the tumor suppression of TGF- $\beta$ pathway.

\begin{abstract}
Abbreviations
HCC: Hepatocellular cancer; TGF- $\beta$ : The transforming growth factor $\beta$; SBE: Smad-binding elements; ELF: Embryonic Liver Fodrin; $\beta 2 S P$ : $\beta 2$-spectrin; TNM: Tumor-node-metastasis; IRS: Immunoreactivity score; CT: Computed tomography; MRI: Magnetic resonance imaging; PET-CT: Positron emission tomography -CT; DFS: Disease Free Survival; OS: Overall Survival; AFP: Alphafetoprotein; HBsAg: Hepatitis B surface antigen; PLT: Platelet; PVTT: Portal vein tumor thrombi. HR, hazard ratio; Cl: Confidence interval.
\end{abstract}

\section{Competing interests}

The authors declare that they have no competing interests.

\section{Authors' contributions}

FJ, SJF and YPH were the main authors of the manuscript. They were involved in the conception, design and coordination of the study as well as in data analysis, interpretation of results and drafting the manuscript. YPH was in charge of all experimental procedures. SLS, LZ, QHC, SQL, BGP, and $L L$ participated in the experimental procedures and revised critically the content of the manuscript. All authors contributed to the interpretation of data and critically revised the manuscript. All authors read and approved the final manuscript.

\section{Acknowledgments}

This study was supported by grants from the National Natural Science Foundation of China (NO. 81201918), Science and Technology Project of Guangdong Province (No.2012B031800099), Doctorial Fellowship of Higher Education of China (NO.200805581172). The funders had no role in study design, data collection and analysis, decision to publish, or preparation of the manuscript.

\section{Author details \\ 'Organ Transplant Center, the First Affiliated Hospital, Sun Yat-sen University, Guangzhou 510080, P. R. China. ${ }^{2}$ Department of Hepatopancreaticobiliary Surgery, The Second Affiliated Hospital of Guangzhou University of Chinese Medicine (Guangdong Provincial Hospital of TCM), Guangdong Provincial Hospital of Traditional Chinese Medicine, Guangzhou 510120, P. R. China. ${ }^{3}$ Department of Liver Surgery, the First Affiliated Hospital, Sun Yat-sen University, Guangzhou 510080, P. R. China. ${ }^{4}$ Laboratory of Surgery, the First Affiliated Hospital, Sun Yat-sen University, Guangzhou 510080, P. R. China. ${ }^{5}$ Department of Pathology, the First Affiliated Hospital, Sun Yat-sen University, Guangzhou 510080, P. R. China.}

Received: 19 November 2014 Accepted: 24 February 2015 Published online: 11 March 2015

\section{References}

1. El-serag HB, Rudolph KL. Hepatocellular carcinoma:epidemiology and molecular carcinogenesis. Gastroenterology. 2007;132:2557-76.

2. Tang ZY. Hepatocellular carcinoma-cause, treatment, and metastasis. World J Gastroenterol. 2001;7:445-54.

3. World Health Organization: The world health report 2006. http://www.who. int/whr/2006/en/
4. Ng KK, Lo CM, Liu CL, Poon RT, Chan SC, Fan ST. Survival analysis of patients with transplantable recurrent hepatocellular carcinoma: implications for salvage liver transplant. Arch Surg. 2008;143:68-74.

5. Kim DY, Paik YH, Ahn SH, Youn YJ, Choi JW, Kim JK, et al. PIVKA-II is a useful tumor marker for recurrent hepatocellular carcinoma after surgical resection. Oncology. 2007;72:52-7.

6. Zarzynska JM. Two Faces of TGF-Beta1 in Breast Cancer. Mediators Inflamm. 2014;2014:141747.

7. Heldin $\mathrm{CH}$, Landström M, Moustakas A. Mechanism of TGF- $\beta$ signaling to growth arrest, apoptosis, and epithelialmesenchymal transition. Curr Opin Cell Biol. 2009;21:166-76.

8. Ikushima $H$, Miyazono K. Biology of transforming growth factor- $\beta$ signaling. Curr Pharm Biotechnol. 2011;12:2099-107.

9. Moses $\mathrm{H}$, Barcellos-Hoff MH. TGF- $\beta$ biology in mammary development and breast cancer. Cold Spring Harb Perspect Biol. 2011;3:a003277.

10. Parvani JG, Taylor MA, Schiemann WP. Noncanonical TGF- $\beta$ signaling during mammary tumorigenesis. J Mammary Gland Biol Neoplasia. 2011;16:127-46

11. Katz LH, Li Y, Chen JS, Muñoz NM, Majumdar A, Chen J, et al. Targeting TGF- $\beta$ signaling in cancer. Expert Opin Ther Targets. 2013;17:743-60.

12. Bierie B, Moses HL. Transforming growth factor beta (TGF- $\beta$ ) and inflammation in cancer. Cytokine Growth Factor Rev. 2010;21:49-59.

13. Kajdaniuk D, Marek B, Borgiel-Marek H, Kos-Kudła B. Transforming growth factor $\beta 1$ (TGF $\beta 1$ ) in physiology and pathology. Endokrynol Pol. 2013:64:384-96.

14. Zu X, Zhang Q, Gao R, Liu J, Zhong J, Wen G. Transforming growth factor- $\beta$ signaling in tumor initiation, progression and therapy in breast cancer: an update. Cell Tissue Res. 2012;347:73-84.

15. Malaguarnera G, Giordano M, Paladina I, Berretta M, Cappellani A, Malaguarnera M. Serum markers of hepatocellular carcinoma. Dig Dis Sci. 2010;55:2744-55.

16. Hua YP, Li SQ, Lai JM, Liang LJ, Peng BG, Liang HZ, et al. Changes in TGF- $\beta$ / Smads signaling pathway in rats with chemical hepatocarcinogenesis. J South Med Univ. 2008;28:1848-52.

17. Baek HJ, Lim SC, Kitisin K, Joqunoori W, Tang Y, Marshall MB, et al. Hepatocellular cancer arises from loss of transforming growth factor beta signaling adaptor protein embryonic liver fodrin through abnormal angiogenesis. Hepatology. 2008:48:1128-37.

18. Thenappan A, Shukla V, Abdul Khalek FJ, Thenappan A, Shukla V, Abdul Khalek FJ, et al. Loss of transforming growth factor $\beta$ adaptor protein $\beta-2$ spectrin leads to delayed liver regeneration in mice. Hepatology. 2011:53:1641-50.

19. Wang Z, Song Y, Tu W, He X, Lin J, Liu F. $\beta$-2 spectrin is involved in hepatocyte proliferation through the interaction of TGF $\beta / S m a d$ and PI3K/AKT signaling. Liver Int. 2012;32:1103-11.

20. Tang $Y$, Katuri $V$, Srinivasan R, Foqt F, Redman R, Anand G, et al. Transforming growth factor-beta suppresses nonmetastatic colon cancer through Smad4 and adaptor protein ELF at an early stage of tumorigenesis. Cancer Res. 2005;65:4228-37.

21. Mishra L, Katuri $V$, Evans S. The role of PRAJA and ELF in TGF-beta signaling and gastric cancer. Cancer Biol Ther. 2005;4:694-9.

22. Tang Y, Kitisin K, Jogunoori W, Li C, Deng CX, Mueller SC, et al. Progenitor/ stem cells give rise to liver cancer due to aberrant TGF- beta and IL-6 signaling. Proc Natl Acad Sci U S A. 2008;105:2445-50.

23. Kim SS, Shetty K, Katuri V, Kitisin K, Baek HJ, Tang Y, et al. TGF-beta signaling pathway inactivation and cell cycle deregulation in the development of gastric cancer: role of the beta-spectrin, ELF. Biochem Biophys Res Commun 2006:344:1216-23.

24. Kitisin K, Ganesan N, Tang Y, Joqunoori W, Volpe EA, Kim SS, et al. Disruption of transforming growth factor-beta signaling through betaspectrin ELF leads to hepatocellular cancer through cyclin D1 activation. Oncogene. 2007;26:7103-10.

25. Bruix J, Sherman M. Management of hepatocellular carcinoma: an update. Hepatology. 2011;53:1020-2.

26. Sobin LH, Wittekind C. UICC (International Union against Cancer) TNM classification of malignant tumors. 6th ed. New York: John Wiley; 2002. p. 1-264.

27. Edmondson HA, Steiner PE. Primary carcinoma of the liver: a study of 100 cases among 48,900 necropsies. Cancer. 1954;7:462-503.

28. Weichert W, Röske A, Gekeler V, Beckers T, Ebert MP, Pross M, et al Association of patterns of class I histone deacetylase expression with 
patient prognosis in gastric cancer: a retrospective analysis. Lancet Oncol. 2008:9:139-48.

29. Wu F, Liu SY, Tao YM, Ou DP, Fang F. Decreased expression of methyl methansulfonate and UV sensitive gene clone 81 is related to poor prognosis of patients with hepatocellular carcinoma. Cancer. 2008;112:2002-10.

30. Wu F, Yang LY, Li YF, Ou DP, Chen DP, Fan C. Novel role for epidermal growth factor-like domain 7 in metastasis of human hepatocellular carcinoma. Hepatology. 2009:50:1839-50.

31. Tripsianis G, Papadopoulou E, Romanidis K, Katotomichelakis M, Anagnostopoulos K, Kontomanolis E, et al. Overall Survival and Clinicopathological Characteristics of Patients with Breast Cancer in Relation to the Expression Pattern of HER-2, IL-6, TNF- $\alpha$ and TGF- $\beta 1$. Asian Pac J Cancer Prev. 2013;14:6813-20.

32. de Kruijf EM, Dekker TJ, Hawinkels LJ, Putter H, Smit VT, Kroep JR, et al. The prognostic role of TGF- $\beta$ signaling pathway in breast cancer patients. Ann Oncol. 2013;24:384-90.

33. Song $\mathrm{S}$, Maru DM, Ajani JA, Chan CH, Honjo S, Lin HK, et al. Loss of TGF- $\beta$ adaptor $\beta 2 \mathrm{SP}$ activates notch signaling and SOX9 expression in esophageal adenocarcinoma. Cancer Res. 2013;73:2159-69.

34. Baek HJ, Pishvaian MJ, Tang Y, Kim TH, Yang S, Zouhairi ME, et al. Transforming growth factor- $\beta$ adaptor, $\beta 2$-spectrin, modulates cyclin dependent kinase 4 to reduce development of hepatocellular cancer. Hepatology. 2011;53:1676-84.

35. Katuri V, Tang Y, Marshall B, Rashid A, Jogunoori W, Volpe EA, et al. Inactivation of ELF/TGF-beta signaling in human gastrointestinal cancer. Oncogene. 2005;24:8012-24.

36. Baek HJ, Kim SS, da Silva FM, Volpe EA, Evans S, Mishra B, et al. Inactivation of TGF-beta signaling in lung cancer results in increased CDK4 activity that can be rescued by ELF. Biochem Biophys Res Commun. 2006:346:1150-7.

37. Li SX, Tang GS, Zhou DX, Pan YF, Tan YX, Zhang J, et al. Prognostic significance of cytoskeleton- associated membrane protein 4 and its palmitoyl acyltransferase DHHC2 in hepatocellular carcinoma. Cancer. 2014;120:1520-31

\section{Submit your next manuscript to BioMed Central and take full advantage of:}

- Convenient online submission

- Thorough peer review

- No space constraints or color figure charges

- Immediate publication on acceptance

- Inclusion in PubMed, CAS, Scopus and Google Scholar

- Research which is freely available for redistribution 